\section{Too much hype}

\section{Scientists have to promote their work. But they should fight the pull to oversell it, says Monika Maleszewska.} f you had asked me a few years ago what makes a scientist, I would have said curiosity. Now, after almost three years pursuing my $\mathrm{PhD}$, I would probably say political skills. Genuine curiosity does indeed make a good scientist, but the ability to promote one's work makes a successful one.

No matter how driven they are, researchers need more than expertise and bright ideas: they need money. Young scientists seeking funding must be ready to enter a world for which their degrees have not prepared them - a world of administrative and funding-agency politics, in which they must promote their ideas to gain attention and receive grants. But they also must take care to avoid crossing the line between promotion and hype.

In the competitive and expensive world of modern science, researchers cannot afford to toil away on their own. Lone-wolf scientists might have their own vision of innovative, cutting-edge research that will reap rewards. But they will probably struggle to procure enough funding to do that work. A hybrid approach might be to secure money through grant applications for 'fashionable' work (with a pinch of hype where necessary), and to hope that the resulting funding will, somewhere along the way, let the visionary scientist pursue his or her dream project the one that really has an impact.

As a young scientist learning to navigate these issues, I often hear the following advice: communicate more effectively. If your project is in basic science or is difficult to understand, people say, make it simpler. Nicer. Easier to digest. Yet scientists thrive on precision. So sometimes, when pressed to make our projects sound simpler and more attractive, we choose hype as an easy way out.

Fashionable keywords, which change almost seasonally, help our projects to sound more relevant to the current trends. Society expects science to have applications, so we readily slip in some socially relevant perspective. A bit of exaggeration about expected results or future uses does not bother our consciences, as long as we perceive it as unbridled enthusiasm.

A skilful presentation and a positive attitude can make a huge difference in how a scientist's work is perceived. Give two $\mathrm{PhD}$ students the same set of data to present, and

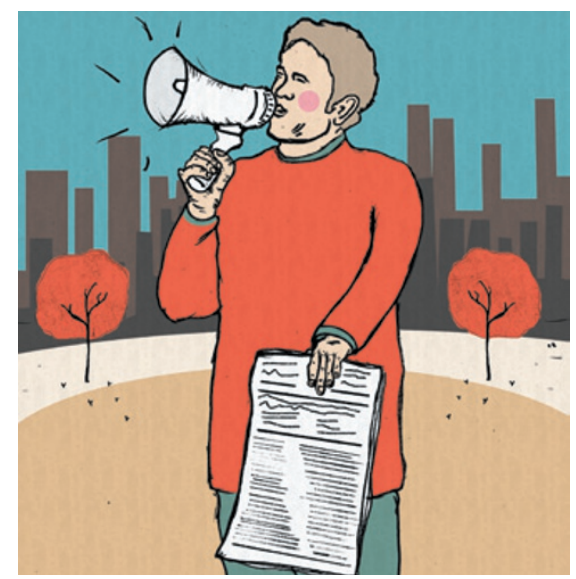

one may put the audience to sleep with dry delivery, whereas the other might spark a vigorous discussion, perhaps winning a collaborator.

Yet despite being under constant pressure as we climb the ranks of academia, scientists must learn to navigate the blurred line between hype and savvy promotion. Young researchers who frequently exaggerate the implications of their findings or make hasty conclusions risk harming their reputations and losing the trust of their colleagues.

I often wish that scientists had the luxury of being able to do basic research just because it is interesting. But reviewers sometimes gravitate towards the projects that provide direct solutions to burning problems, rather than to basic projects with no clear applications. We must give basic projects a chance, especially because breakthroughs are hard to anticipate. That basic science might be closer to a meaningful application than anyone expects.

In the competitive world of scientific funding, researchers often have no choice but to hone their political skills and manage public relations for their research. Ideally, they will be able to do this without taking too much time away from the science. What's clear is that budding researchers must learn how to promote their work, and perhaps even become trendsetters - without resorting to hype.

Monika Maleszewska is a graduate student in regenerative medicine at the University of Groningen in the Netherlands.

\section{PUBLISHING}

\section{Fashion rules in physics}

Physicists are fad-followers who often pursue the fields with the highest number of recently published papers, says a study (T. Wei et al. Sci. Rep. 3, 2207; 2013). The metareview, of around 320,000 articles published by the American Physical Society's Physical Review journals from 1976 to 2009 , also found that papers with many authors, which are common in some areas of physics, tend to be on 'hot' research topics. Working in a hot field can be a good strategy, says lead author Jinshan Wu, a physicist at Beijing Normal University, because it can increase citations, attention from peers and research funding. But, he notes, the scientific community can suffer if leaders are not exploring new directions.

\section{EUROPEAN UNION}

\section{Grant popularity soars}

A 50\% spike in demand for European Research Council (ERC) Starting Grants has pulled this year's success rate down to $9 \%$, and is likely to lead to changes in some eligibility requirements. ERC president Helga Nowotny says that the increase to 3,329 applications this year, of which 287 were successful — is attributable in part to research-budget cuts in some European nations. The ERC, based in Brussels, will consider lengthening the period between resubmissions to reduce the flow of applications, she adds. Starting Grants, now in their sixth year, fund researchers who finished their doctorate in the past 2-7 years. This year, the ERC spent nearly $€ 400$ million (US\$527 million) on the awards, which are worth up to $€ 2$ million each and last for up to five years.

\section{FUND-RAISING}

\section{Art sales fund science}

Sales of stylized scientific images, including micrographs of human-heart and mousebrain cells, are helping to pay for earlycareer researchers to travel. Proceeds from an art fair and website (go.nature.com/ aakuwa) have raised some US $\$ 30,000$ so far, enough to send 60 graduate students and postdocs from the University of Michigan in Ann Arbor to conferences. And there is another benefit: "We started this as a fund-raiser, but it turns out to be an awesome public-outreach tool," says Deborah Gumucio, founder of the Michigan Center for Organogenesis, which runs the Bio-Artography project. "People come into our fair booth and we can talk to them about pluripotent stem cells." 